\title{
Macroscopic Findings Group Identifier
}

National Cancer Institute

\section{Source}

National Cancer Institute. Macroscopic Findings Group Identifier. NCI Thesaurus. Code C119860.

A character or string that represents a macroscopic findings group. 